\title{
Modelling the relationship between water level and vertical displacements on the Yamula Dam, Turkey
}

\author{
T. Bayrak \\ Institute for Aksaray University, Engineering Faculty, Department of Geodesy and Photogrammetry Engineering, 68100, \\ Aksaray, Turkey
}

Received: 7 February 2007 - Revised: 27 March 2007 - Accepted: 27 March 2007 - Published: 10 April 2007

\begin{abstract}
Monitoring deformation pattern of dams is often one of the most effective ways to understand their safety status. The main objective of the study is to find the extent to which rising reservoir level affects the mechanism of deformation of The Yamula Dam under certain change in the reservoir level conditions during to the first filling period. Three different deformation analysis techniques, namely static, kinematic and dynamic, were used to analyze four geodetic monitoring records consisting of vertical displacements of nine object points established on the Dam and six reference points surrounding of it, to see whether the rising reservoir level have a role in the vertical deformations during the first filling period. The largest vertical displacements were in the middle of the dam. There is an apparent linear relationship between the dam subsidence and the reservoir level. A dynamic deformation model was developed to model this situation. The model infers a causative relationship between the reservoir level and the dam deformations. The analysis of the results determines the degree of the correlation between the change in the reservoir level and the observed structural deformation of the dam.
\end{abstract}

\section{Introduction}

The failure of several major dams, i.e. the Malpasset Dam (France, 1958) and the Vajont Dam (Italy, 1963), causing major destruction and high death toll led to a systematic monitoring of major dams and reservoir in order to insure their structural integrity, the prevention of major damage, and especially, the safety of the public. Therefore thousands of dams all over the world have been systematically surveyed for relatively long ( $>10$ years) periods on the basis of geodetic and geo-technical methods (Pytharouli and Stathis, 2005).

Correspondence to: T. Bayrak

(tbayrak@nigde.edu.tr)
Driven by the development of measuring and analysis techniques, the goal of the geodetic deformation analysis is nowadays to proceed from a merely phenomenological description of the deformation of an object to the analysis of the process which caused the deformation (Welsh, 2003). Analysis of deformations of any type of a deformable body includes geometrical analysis and physical interpretation. Geometrical analysis describes the change in shape and dimensions of the monitored object. The ultimate goal of the geometrical analysis is to determine in whole deformable object the displacements and strain fields in the space and domains. Physical interpretation is to establish the relationship between the causative factors (loads) and the deformations. This can be determined either by statistical method, which analyses the correlation between the observed deformations and loads (Chrzanowski at al., 2005).

In this study, intend to show, as an example, effect of pressure of water on the dam settlement during the first filling of reservoir with the geodetic monitoring results using statistical method, which analyses the correlation between the observed deformations and loads. Thus, it is analyzed four geodetic records covering the first filling period, described the subsidence of the body of a large size earthfill dam, called The Yamula, and tried to investigate the effect of the increase of the reservoir level on the dam. The problem is, how the rising water level of the reservoir effects the vertical deformations of the dam during the first filling period. Geodetic deformation models called static, kinematic and dynamic were used to answer this question. With the static model, only parameters of vertical displacements were computed. In addition to the vertical displacements, velocity and acceleration parameters of the vertical displacements were computed with the kinematic model. The static and the kinematic models cannot include the effect of the rising reservoir level. The dynamic model contains the calculation of a parameter of the rising reservoir level, which shows the geometric signature of the physical effect. Finally, the acceleration effect of rising

Published by Copernicus GmbH on behalf of the European Geosciences Union. 


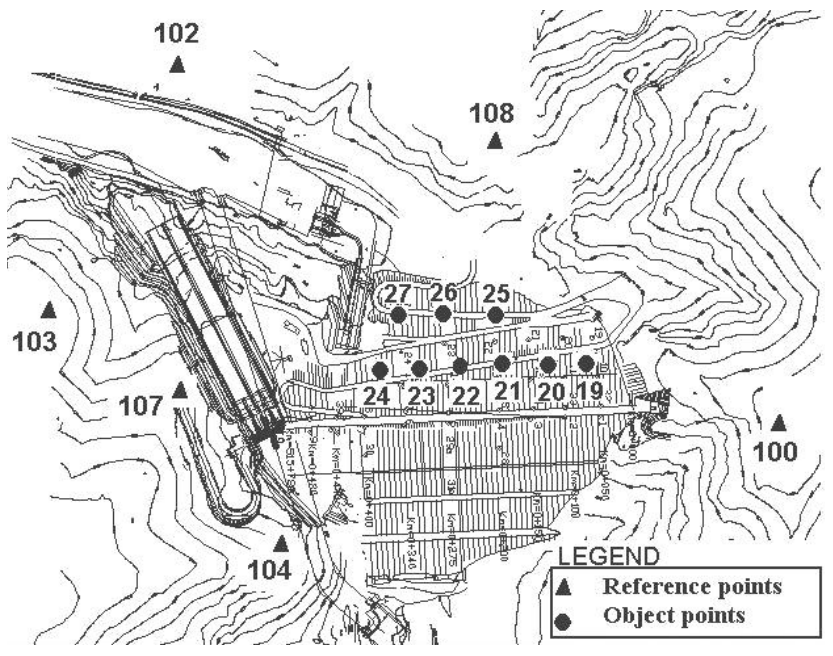

Fig. 1. Geodetic monitoring scheme for The Yamula Dam.

level in large reservoirs on the dam deformations was investigated. The results from three models were compared and interpreted.

\section{The Yamula Dam and geodetic deformation monitor- ing system}

The Yamula Dam, on the Kizllırmak River, is a large $(120 \mathrm{~m}$ in hight, with a $510 \mathrm{~m}$ in long crest) earthfill dam. This \$1-billion project, located near $(2 \mathrm{~km})$ the Yamula town and near $(40 \mathrm{~km})$ the Kayseri province of central Turkey (approximately $320 \mathrm{~km}$ SE of the capital city Ankara) was designed to secure water for about 0.7 million inhabitants. The (Turkish) Ayen Energy Joint-Stock Company constructed it between 2000 and 2005. It was put into service in 2005 in order to store water for the generation of electricity (storage capacity approximately $3476.00 \times 10^{6} \mathrm{~m}^{3}$ ) and to control river flooding. The dam is constructed by earthen material taken from the riverbed of the Kizılırmak River. The impermeable clay core of the dam is protected by semi-permeable material. First filling period started in December 2003 and ended in April 2005.

To ensure its structural integrity, prevention of major damage and, especially, safety of the public, the dam was monitored by geodetic techniques using a deformation network (Fig. 1). Figure 1 shows distribution of reference and object points of geodetic monitoring scheme. The aim of the geodetic deformation monitoring system of the Yamula Dam is to detect possible vertical displacements. In addition, with properly designed these monitoring surveys, the second aim of the deformation monitoring system is also to determine the actual deformation mechanism and to explain the causes of deformation in case of an abnormal behaviour of the investigated object. The geodetic deformation monitoring system includes a number of object points on the dams and a network of local reference stations with respect to which displacements of the object points are to be determined. Monitoring network consists of six reference stations $(100,102$, $103,104,107,108)$ established surroundings of the dam and of nine object points $(19,20,21,22,23,24,25,26,27)$ on surface of the dam's downstream face.

The original data were recorded by hand. A data sheet was filled in for each measuring epoch, and included measurements of height data, time of measurement, reservoir level, and ambient temperature. The data were transferred into a digital database, and were cleaned of from gross errors. The deformation measurements of the dam involved four measurement campaigns. The height data were measured using a Total Station (Sokkia 530R). The manufacturer specifies the standard deviation of the distance measurements as $\pm(2 \mathrm{~mm}+2 \mathrm{ppm})$. The deformation network was designed to detect displacements of targeted points on the downstream faces of the dams with an accuracy of $10 \mathrm{~mm}$ at the $95 \%$ confidence level. The accuracy of the vertical displacements was calculated as $\pm 9 \mathrm{~mm}$ (maximum value) from network adjustment. The first campaign was carried out in December 2003, the second in March 2004, the third in November 2004 and the last one in April 2005. These measurements were all made during the first filling period of the dam. Three different deformation analysis techniques were used to analyze four epochs of data.

\section{Static analysis}

The starting point of the static deformation (global congruency test) analysis is the hypothesis test that detects height differences and, thus, movements of object points between two epochs. These tests are computed for the data of two observation campaigns using the linear Gauss-Markoff model. The static analysis follows the traditional Hannover approach of deformation analysis. In the application of deformation analysis, each epoch is adjusted separately as a free network. If the monitoring network comprises reference points and object points, the parameter network is partitioned accordingly into the sub-vector $\underline{x}^{r}$, referring to the reference block, and $\underline{x}^{0}$, referring to object points. The problem of investigation of the stability of the reference block is solved by a test of the null hypothesis $H_{0}$ (the common points of both epochs are stable and, thus, have the same expectation of the estimated positions)

$H_{0}: \underline{\mathrm{x}}_{1}^{r}-\underline{\mathrm{x}}_{2}^{r}$

provided that both of the models are based on the same geodetic datum. For the global test of common points, the equations are

$\underline{d}_{f}=\underline{\mathrm{x}}_{r 2}^{i}-\underline{\mathrm{x}}_{r 1}^{i}$

$\left(\underline{Q}_{d d}\right)_{r}=\left(\underline{Q}_{r r}^{i}\right)_{1}+\left(\underline{Q}_{r r}^{i}\right)_{2}$ 
$\underline{R}=\underline{d}_{r}^{T}\left(\underline{Q}_{d d}\right)_{r}^{+} \underline{d}_{r}$

$s_{0}^{2}=\frac{f_{1} s_{01}^{2}+f_{2} s_{02}^{2}}{f_{1}+f_{2}}$

$T=\frac{R}{s_{0}^{2} h_{r}}$

where $\underline{d}_{f}=$ difference vector of the coordinates; $\left(\underline{Q}_{d d}\right)_{r}^{+}=$ Moore-Penrose inverse of the common cofactor matrix; subscripts 1 and 2 indicate the respective epoch; $f_{1}$ and $f_{2}=$ freedom of the network at first and second epoch; $s_{01}^{2}$ and $s_{02}^{2}=$ variance factors; $s_{0}^{2}=$ common variance; $\underline{r}_{g}$, denotes the rank; and $F$, denotes the Fisher distribution.

$h=\underline{r}_{g}\left(\underline{Q}_{x 1}^{r}+\underline{Q}_{x 2}^{r}\right)$

If

$T>F(h, f ; 1-\alpha)$

then the null hypothesis is rejected. The point in reference block whose contribution to the quadric form $R$ is maximum is considered responsible for the rejection of $H_{0}$. This procedure is carried out until the null hypothesis is satisfied (Niemeier, 1977; Koch, 1999; Caspary, 1987; Denli and Deniz, 2003; Yalçınkaya, 2003).

The static deformation model is the most basic model. The static model can only determine displacements. For comparison with the kinematic and dynamic models, the results of static model of the object points for the December 2003November 2004 and December 2003-April 2005 are given in Tables 1 and 2. It wasn't determined any significant settlement of the object points for epoch of December 2003March 2004. The vertical movements (dh) and the statistical test values $\left(\mathrm{T}_{d h}\right)$ in Tables 1 and 2 were calculated according to Koch (1999). The test values were compared with the $F$-distribution values (q) to see whether the movements of object points were significant or not. The stable and unstable points are shown in the decision column.

\section{Kinematic analysis}

In this model, it is attempted to refine three unknown model parameters from sets of three observation epochs of the network. A time-dependent one-dimensional kinematical model consisting of position, velocity and acceleration was formed according to.

$x_{j}^{(i)}=x_{j}^{(i-1)}+\left(t_{i}-t_{i-1}\right) v_{x j}+\frac{1}{2}\left(t_{i}-t_{i-1}\right)^{2} a_{x j}$

where $x_{j}^{(i)}=$ coordinate of point $j$ at period $(i) ; x_{j}^{(i-1)}=$ coordinate of point $j$ at period $(i-1) ; v_{x j}=$ velocity of $\mathrm{x}$ coordinate of point $j ; a_{x j}=$ acceleration of x coordinate of point $j$; $t_{i}=$ time of measurement epoch $(i) ; t_{i-1}=$ time of measurement epoch $(i-1) ; i=1,2, \ldots, k(k=$ measurement epoch number); and $j=1,2, \ldots, n(n=$ point number $)$.
Table 1. Vertical displacements for December 2003-November 2004.

\begin{tabular}{ccccc}
\hline PN & dh $(\mathrm{cm})$ & Test Value $\left(\mathrm{T}_{d h}\right)$ & F-test $(\mathrm{q})$ & Decision \\
\hline 19 & & & & Stable \\
20 & & & & Stable \\
21 & -5.26 & 9.015 & 2.746 & $\mathrm{~T}_{d h}>\mathrm{q}$ Unstable \\
22 & -5.54 & 12.701 & 2.651 & $\mathrm{~T}_{d h}>\mathrm{q}$ Unstable \\
23 & -8.01 & 27.751 & 2.458 & $\mathrm{~T}_{d h}>\mathrm{q}$ Unstable \\
24 & -2.97 & 4.852 & 2.867 & $\mathrm{~T}_{d h}>\mathrm{q}$ Unstable \\
25 & & & & Stable \\
26 & & & & Stable \\
27 & & & & Stable \\
\hline
\end{tabular}

Table 2. Vertical displacements for December 2003-April 2005.

\begin{tabular}{ccccc}
\hline PN & dh $(\mathrm{cm})$ & Test Value $\left(\mathrm{T}_{d h}\right)$ & F-test $(\mathrm{q})$ & Decision \\
\hline 19 & & & & Stable \\
20 & & & & Stable \\
21 & -5.61 & 7.204 & 2.651 & $\mathrm{~T}_{d h}>\mathrm{q}$ Unstable \\
22 & -7.09 & 12.875 & 2.458 & $\mathrm{~T}_{d h}>\mathrm{q}$ Unstable \\
23 & -10.79 & 24.299 & 2.372 & $\mathrm{~T}_{d h}>\mathrm{q}$ Unstable \\
24 & -5.36 & 9.545 & 2.575 & $\mathrm{~T}_{d h}>\mathrm{q}$ Unstable \\
25 & -1.88 & 3.202 & 3.026 & $\mathrm{~T}_{d h}>\mathrm{q}$ Unstable \\
26 & -3.06 & 4.232 & 2.746 & $\mathrm{~T}_{d h}>\mathrm{q}$ Unstable \\
27 & -3.14 & 3.756 & 2.867 & $\mathrm{~T}_{d h}>\mathrm{q}$ Unstable \\
\hline
\end{tabular}

In Eq. (9), the unknown movement parameters consist of position, velocity (first derivative of position) and acceleration (second derivative of position). The three unknown parameters can be calculated using the Kalman-Filter technique with three measurement periods. In the Kalman-Filter technique, the movement parameters at the present time are predicted with those of the preceding $\left(t_{i-1}\right)$ period. Finally, the filtered (adjusted) parameters are computed, combining the predicted information and the measurements at the $t_{i}$ period. To compute the movement parameters of the points with the Kalman-Filter technique, equations of position, velocity and acceleration can be written as below (Pelzer, 1986; Grewal and Andrews, 1993; Yalçınkaya and Bayrak, 2005).

$x_{j}^{(i)}=x_{j}^{(i-1)}+\left(t_{i}-t_{i-1}\right) v_{x j}+\frac{1}{2}\left(t_{i}-t_{i-1}\right)^{2} a_{x j}$

$v_{x j}^{(i)}=v_{x j}+\left(t_{i}-t_{i-1}\right) a_{x j}$

$\mathrm{a}_{x j}^{(i)}=a_{x j}$

Equations (10), (11), and (12) can be represented in matrix form

$\left.\overline{Y_{i}}=\left[\begin{array}{c}x \\ v_{x} \\ a_{x}\end{array}\right]_{i}=\left[\begin{array}{ccc}I I\left(t_{i}-t_{i-1}\right) & I \frac{1}{2}\left(t_{i}-t_{i-1}\right)^{2} \\ 0 & I & I\left(t_{i}-t_{i-1}\right) \\ 0 & 0 & I\end{array}\right]\right]_{i-1}$ 
Table 3. Statistical tests of the kinematic model.

\begin{tabular}{llllll}
\hline \multicolumn{2}{r}{${ }^{\mathrm{a}}$ Linear Model (Postion + Velocitiy) } & ${ }^{\mathrm{b}}$ Square Model (Postion + Velocitiy + Acceleration) & ${ }^{\mathrm{c}}$ Square Model (Postion + Velocitiy + Acceleration) \\
\hline Global Test & Expanded Model Test & Global Test & Expanded Model Test & Global Test & Expanded Model Test \\
$\mathrm{s}_{0}$ & $\mathrm{~m}_{0}$ & $\mathrm{~m}_{L}$ & $\mathrm{~m}_{S 1}$ & $\mathrm{~m}_{L}$ & $\mathrm{~m}_{S 3}$ \\
$\mathrm{~m}_{0}$ & $\mathrm{~m}_{L}$ & $\mathrm{~m}_{S 1}$ & $\mathrm{~m}_{S 2}$ & $\mathrm{~m}_{S 3}$ & $\mathrm{~m}_{S 3}$ \\
$\mathrm{~T}$ & $\mathrm{~T}_{L}$ & $\mathrm{~T}_{S 1}$ & $\mathrm{~T}_{S 2}$ & $\mathrm{q} S 3$ & $\mathrm{~T}_{S 4}$ \\
$\mathrm{q}$ & $\mathrm{q}_{L}$ & $\mathrm{q}_{S 1}$ & $\mathrm{q}_{S 2}$ & 0.695 & 0.814 \\
0.646 & 0.695 & 0.695 & 0.705 & 0.814 & 2.802 \\
0.695 & 2.148 & 0.705 & 3.012 & 1.372 & 11.849 \\
1.157 & 9.552 & 1.029 & 19.360 & 1.900 & 2.141 \\
2.652 & 2.307 & 1.900 & 2.141 & $\mathrm{~T}_{S 3}<\mathrm{q}$ & $\mathrm{T}_{S 4}>\mathrm{q}$ \\
$\mathrm{T}<\mathrm{q}$ & $\mathrm{T}_{L}>\mathrm{q}$ & $\mathrm{T}_{S 1}<\mathrm{q}$ & $\mathrm{T}_{S 2}>\mathrm{q}$ & Model is & Model can be \\
Model is & Model can be & Model is & Model can be & VALID & EXPANDED \\
VALID & EXPANDED & VALID & EXPANDED &
\end{tabular}

Note: Decision=position+velocity+acceleration

${ }^{\mathrm{a}}$ December 2003-March $2004{ }^{\mathrm{b}}$ December 2003-March 2004-November $2004{ }^{\mathrm{c}}$ December 2003-March 2004-April 2005

or, in with a shorter form

$\overline{Y_{i}}=T_{i, i-1} \hat{Y}_{i-1}$

where $\overline{Y_{i}}=$ predicted state (position, velocity, acceleration) vector at period $t_{i} ; \hat{Y}_{i-1}=$ state vector at period $t_{i-1} ; T_{i, i-1}=$ transition matrix and $I=$ unit matrix. Equation (14) is the prediction equation, which is the basic equation of a KalmanFilter; $w=$ constant violator acceleration vector and $N=$ the system noise vector. $w$ cannot be measured as a rule. So it can be taken as zero. $N$ is the last column of the $T$ matrix between periods $t_{i}$ and $t_{i-1}$. The prediction equation and covariance matrix in Eq. (14) can be rewritten as

$\overline{Y_{i}}=T_{i, i-1} \hat{Y}_{i-1}+N_{i, i-1} w_{i-1}$

$Q_{\overline{Y Y}, i}=T_{i, i-1} Q_{\hat{Y} \hat{Y}, i-1} T_{i, i-1}^{T}+N_{i, i-1} Q_{w w, i-1} N_{i, i-1}^{T}$

where $Q_{\hat{Y} \hat{Y}, i-1}=$ cofactor matrix of the state vector; and $Q_{w w, i-1}=$ cofactor matrix of the system noise at time $t_{i-1}$. $Q_{w w, i-1}$ can be predicted as follows.

$Q_{w w, i-1}=4\left(t_{i}-t_{i-1}\right)^{-4} Q_{\hat{Y} \hat{Y}, i-1}$

The adjustment of the problem can be expressed in matrix form as

$l_{i}+v_{1, i}=A_{i} \hat{Y}_{i}$

where $l_{i}, v_{1, i}, A$, and $\hat{Y}_{i}=$ measurements in epoch $i$, residuals, coefficients matrix, and state vector at time $t_{i}$, respectively. The functional and stochastic models for the KalmanFilter technique combining Eqs. (15) and (18) can be written in matrix form as

$$
\left[\begin{array}{c}
\bar{Y}_{i} \\
l_{i}
\end{array}\right]=\left[\begin{array}{c}
I \\
A_{i}
\end{array}\right] \hat{Y}_{i}-\left[\begin{array}{c}
v_{\bar{Y}, i} \\
v_{1, i}
\end{array}\right] ; \quad Q_{i}=\left[\begin{array}{cc}
Q_{\overline{Y Y}, i} & 0 \\
0 & Q_{l l, i}
\end{array}\right]
$$

The model is solved and the movement parameters and their cofactor matrix are computed. Thus, with the Kalman-Filter technique, the three unknown parameters can be computed

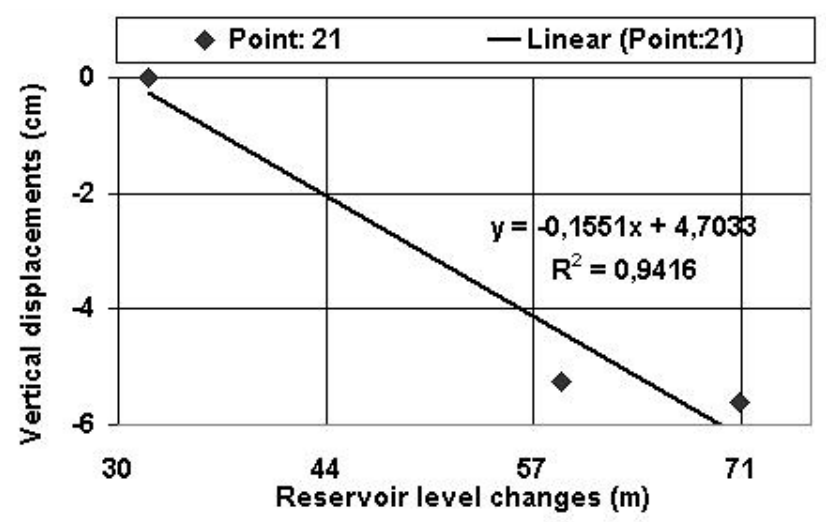

Fig. 2. Relationship between the reservoir level and the height changes at the point 21 .

with three measurement epochs (Heunecke, 1995; Kuhlman, 2003; Yalçınkaya and Bayrak, 2003; Bayrak and Yalçınkaya, 2003).

As mentioned above, the parameters of position, velocity and acceleration are included in this process. It is statistically determined whether the expansion of the kinematic model with velocity and acceleration parameters is significant according to Koch (1999). The kinematic model for the vertical displacements on the dam was solved by the Kalman-Filter technique. The kinematic model was calculated step-by-step. The results of global test and expanded model test are shown in Table 3. Where a priori variance $\left(s_{0}\right)$ was computed in a preliminary network adjustment. A posteriori variance $\left(m_{0}\right)$ was computed from ${ }^{a}$ Linear Model. $T=m_{0}^{2} / s_{0}^{2}$. q is the $F$-distribution value. According to Koch (1999), if $T<q$, the global test is valid. As can be seen from Table 3, all global test values $\left(T, T_{S 1}, T_{S 3}\right)$ are little than the $\alpha$-percentage point of the $F$-distribution value (q) for a confidence level of $\alpha=0.05$. Thus, the linear and the square models can be viewed as accurate enough for this confidence level. That is, 
Table 4. Movement parameters for December 2003-March 2004-November 2004.

\begin{tabular}{|c|c|c|c|c|c|c|c|c|c|}
\hline \multirow{2}{*}{${ }^{\text {aP.N. }}$} & \multicolumn{3}{|c|}{ Height Difference ( $\mathrm{cm}$ ) } & \multicolumn{3}{|c|}{ Velocity cm / month } & \multicolumn{3}{|c|}{ Acceleration $\mathrm{cm} / \mathrm{month}^{2}$} \\
\hline & ${ }^{b} \mathrm{dh}$ & $\mathrm{T}_{d h}$ & Decision & $c_{\mathrm{v}_{h}}$ & $\mathrm{Tv}_{h}$ & Decision & $d_{\mathrm{a}_{h}}$ & $\mathrm{Ta}_{h}$ & Decision \\
\hline 19 & -0.04 & 0.25 & - & 0.00 & 1.48 & - & 0.00 & 1.64 & - \\
\hline 20 & -0.07 & 0.35 & - & 0.00 & 1.81 & - & 0.00 & 0.71 & - \\
\hline 21 & -5.72 & 8.43 & + & -0.30 & 1.60 & - & -0.01 & 0.57 & - \\
\hline 22 & -6.47 & 9.57 & + & -0.31 & 1.67 & - & -0.02 & 0.85 & - \\
\hline 23 & -8.68 & 12.88 & + & -0.85 & 4.67 & + & -0.03 & 1.23 & - \\
\hline 24 & -2.64 & 3.92 & + & -0.08 & 0.43 & - & -0.04 & 1.55 & - \\
\hline 25 & -0.53 & 0.82 & - & -0.05 & 0.70 & - & 0.00 & 0.17 & - \\
\hline 26 & -0.93 & 1.45 & - & -0.06 & 0.87 & - & 0.00 & 0.12 & - \\
\hline 27 & -0.49 & 0.75 & - & -0.02 & 0.26 & - & 0.00 & 0.46 & - \\
\hline \multicolumn{10}{|c|}{$\mathrm{q}_{t}=2.01 \mathrm{~T}>\mathrm{q}_{t}(+) \mathrm{T}<\mathrm{q}_{t}(-)$} \\
\hline
\end{tabular}

${ }^{\mathrm{a}}$ Point number, ${ }^{\mathrm{b}}$ Height Difference, ${ }^{\mathrm{c}}$ Velocity, ${ }^{\mathrm{d}}$ Acceleration

Table 5. Movement parameters for December 2003-March 2004-April 2005.

\begin{tabular}{llllllllll}
\hline \multirow{2}{*}{ a P.N. } & \multicolumn{3}{c}{ Height Difference $(\mathrm{cm})$} & \multicolumn{3}{c}{ Velocity cm/month } & \multicolumn{2}{c}{ Acceleration cm/month $^{2}$} \\
\cline { 2 - 10 } & $\mathrm{b}_{\mathrm{dh}}$ & $\mathrm{T}_{d h}$ & Decision & $\mathrm{c}_{\mathrm{v}_{h}}$ & $\mathrm{Tv}_{h}$ & Decision & $\mathrm{d}_{\mathrm{a}_{h}}$ & $\mathrm{Ta}_{h}$ & Decision \\
\hline 19 & -0.07 & 0.33 & - & 0.00 & 1.31 & - & -0.01 & 1.06 & - \\
20 & -0.11 & 0.42 & - & 0.00 & 1.33 & - & -0.02 & 1.49 & - \\
21 & -5.37 & 3.58 & + & -0.78 & 5.12 & + & -0.05 & 3.35 & + \\
22 & -7.39 & 4.94 & + & -1.04 & 6.84 & + & -0.06 & 4.61 & + \\
23 & -11.93 & 7.98 & + & -1.64 & 10.73 & + & -0.10 & 7.46 & + \\
24 & -5.82 & 3.89 & + & -0.88 & 5.74 & + & -0.05 & 3.94 & + \\
25 & -1.31 & 2.08 & + & -0.42 & 2.89 & + & -0.03 & 2.29 & + \\
26 & -3.15 & 2.27 & + & -0.63 & 4.27 & + & -0.04 & 3.18 & + \\
27 & -2.81 & 2.18 & + & -0.58 & 3.88 & + & -0.04 & 2.87 & + \\
\hline
\end{tabular}

${ }^{\mathrm{a}}$ Point number, ${ }^{\mathrm{b}}$ Height Difference, ${ }^{\mathrm{c}}$ Velocity, ${ }^{\mathrm{d}}$ Acceleration

the global tests of linear and square models are valid.

To decide about an expansion of the kinematic model with the velocity and acceleration, respectively, statistical tests were performed. To perform expanded model test, a priori variance $\left(m_{0}\right)$ was taken from the ${ }^{a}$ Linear Model. A posteriori variance of expanded model $\left(m_{L}\right)$ was computed from parameters of the expanded model. The test value $\left(T_{L}\right)$ were computed with the $m_{0}$ and $m_{L}$ values and compared with the $F$-distribution value $(q)$ to evaluate whether the expansion of the model was significant or not. According to Koch (1999), if $T>q$, the expanded model test is valid. As can be seen from Table 3, all expanded model test values $\left(\mathrm{T}_{L}, \mathrm{~T}_{S 2}, \mathrm{~T}_{S 4}\right)$ are larger than the $\alpha$-percentage point of the $F$-distribution value for a confidence level of $\alpha=0.05$. That is to say, the global tests of linear and square models are valid. Thus, the expansion of the linear and the square models with velocity and acceleration can be carried out respectively.

The most appropriate functional model for the linear and the square models is stated in the "decision" note at the bottom of Table 3 . The movement parameters (vertical displacement, velocity, acceleration) were computed and the results of the object points for the December 2003-March 2004-November 2004 and December 2003-March 2004April 2005 are given in Tables 4 and 5. It wasn't determined any significant settlement of the object points for epoch of December 2003-March 2004. Here, every parameter was divided by its standard deviation, and test values $\left(T_{d h}, T v_{h}\right.$, $T a_{h}$ ) were computed. These values were compared with the t-distribution value $\left(q_{t}\right)$ to evaluate whether they were significant or not. Where parameters have significantly changed, a (+) sign is shown; otherwise, a (-) sign is shown in decision column.

\section{Dynamic analysis}

The first filling period of a dam is the most dangerous and interesting period in its life. At the stage of filling the reservoir, the main two effects must be considered: pressure of water and effect of wetting (Kulkarni at al., 2006; Chrzanowski at al., 2005). In this model, it is shown, as an example, effect of pressure of water on the dam settlement during the 
Table 6. Vertical displacements and reservoir water levels for the point 21 .

\begin{tabular}{lll}
\hline Measurement epochs & WL $(\mathrm{m})$ & $\mathrm{dh}(\mathrm{cm})$ \\
\hline December 2003-March 2004 & 31.99 & 0.00 \\
December 2003-November 2004 & 58.72 & -5.26 \\
December 2003-April 2005 & 70.33 & -5.61 \\
\hline
\end{tabular}

Table 7. The square of correlation coefficient for the moving points.

\begin{tabular}{cc}
\hline Point Number & square of correlation coefficient \\
\hline 21 & 0.94 \\
22 & 0.99 \\
23 & 0.99 \\
24 & 0.97 \\
25 & 0.58 \\
26 & 0.71 \\
27 & 0.51 \\
Average & 0.81 \\
\hline
\end{tabular}

first filling of reservoir with the geodetic monitoring results. Does the reservoir water level affect the vertical deformations of a dam? Is there a relationship between the vertical displacements on a dam and reservoir level? Is there a causative relationship between reservoir water level and dam deformations? To answers these questions for the Yamula Dam, the relationship between the reservoir water level and the vertical displacements were investigated. An attempt was made to correlate the vertical displacements of object points and with water level. The graphic that shows the relationship between the reservoir level and computed subsidence was drawn for point 21 (Fig. 2). Values for the graphic were given in Table 5 where WL is the water level changes between the measurement epochs.

$\mathrm{R}^{2}$ in Fig. 2 is the square of correlation coefficient. $R^{2}$ gives the proportion of sample variety in dependent variable (vertical displacements) that is explained by independent variable (the rise in the reservoir level). For the point $21, \mathrm{R}^{2}$ means that $94.16 \%$ of the variability in the dependent variable is explained by the independent variable and $5.84 \%$ is unexplained. $\mathrm{R}^{2}$ values for the moving points $(21,22,23$, $24,25,26,27)$ are given in Table 7 . As shown in Fig. 2 and Table 7, there is an apparent linear relation between the height changes and the rise in the reservoir level. In addition, there was evidence of the rise in water level in the magnitude of the displacements. This causative relationship was therefore inferred by a developed dynamic model (Table 8). Table 8 shows causative relationship between the rise in the reservoir water level and the dam deformations

As mentioned in the kinematic analysis section, the po-

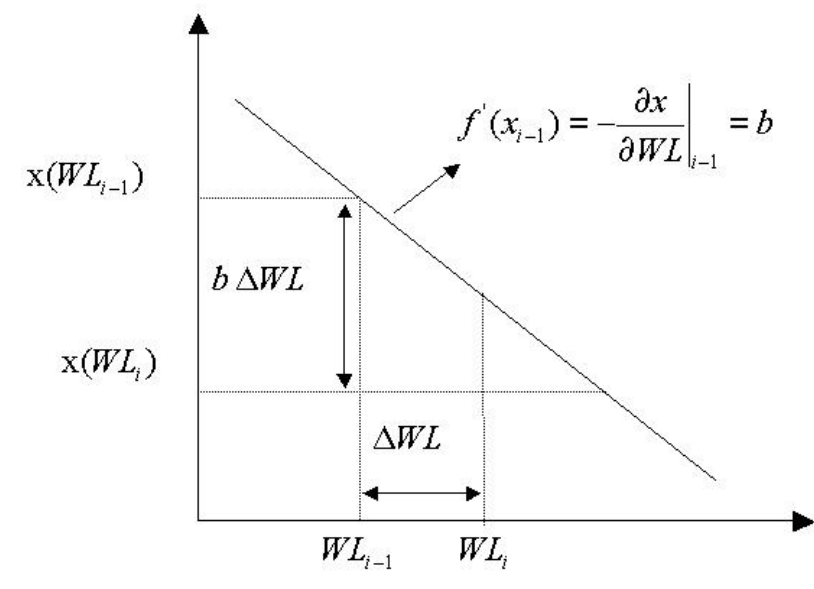

Fig. 3. Causative relationship between the reservoir level and the vertical displacements.

sition variation was written as $x=f(t)$ in Eq. (9) taking into consideration only the time for an accelerated point to capture the influences of all effective forces. The dynamic causes of vertical displacements cannot be described with the kinematic model. A dynamic model can be formed by adding the cause of the movements to this kinematic approach (Pelzer, 1985; Ren and Ding, 1996; Yalçınkaya and Bayrak, 2003, 2005). Thus, Eq. (9) can be extended by the reservoir level, which is one of the causes of the vertical displacements affecting the point positions on the dam, as can be seen by $x=f(t, W L)$. Here $W L$ represents reservoir level changes and is a dynamic variable. If $x=f(t, W L)$ is expanded with a Taylor series to the second degree, Eq. (9) can be extended to

$$
\begin{gathered}
x\left(t_{i}, W L_{i}\right)=x\left(t_{i-1}, W L_{i-1}\right)+\left.\frac{\partial x}{\partial t}\right|_{\left(t_{i-1}\right)} \Delta t-\left.\frac{\partial x}{\partial W L}\right|_{\left(W L_{i-1}\right)} \\
\Delta W L+\left.\frac{1}{2 !} \frac{\partial^{2} x}{\partial t^{2}}\right|_{\left(t_{i-1}\right)} \Delta t^{2}
\end{gathered}
$$

$x\left(t_{i}, W L_{i}\right)=x\left(t_{i-1}, W L_{i-1}\right)+v_{\left(t_{i-1}\right)} \Delta t-b_{\left(W L_{i-1}\right)}$

$$
\Delta W L+\frac{1}{2 !} a_{\left(t_{i-1}\right)} \Delta t^{2}
$$

The relationship between the reservoir water level changes and the vertical displacements is shown in Fig. 3. Where $\Delta W L$ and $\Delta t$ are the difference of reservoir water levels and time differences between the two epochs; and $b$ is the water level parameters. A time dependent one dimensional dynamic model consisting of position, velocity, acceleration and water level can be written as below. In this model, it is attempted to refine four unknown model parameters from four observation epochs of the deformation network.

$$
\begin{aligned}
x_{j}^{(i)}= & x_{j}^{(i-1)}+\left(t_{i}-t_{i-1}\right) v_{x j}+\frac{1}{2}\left(t_{i}-t_{i-1}\right)^{2} \mathrm{a}_{x j} \\
& +\left(W L_{i}-W L_{i-1}\right) b_{x j}
\end{aligned}
$$


Table 8. Causative relationship between the reservoir level and the dam deformations.

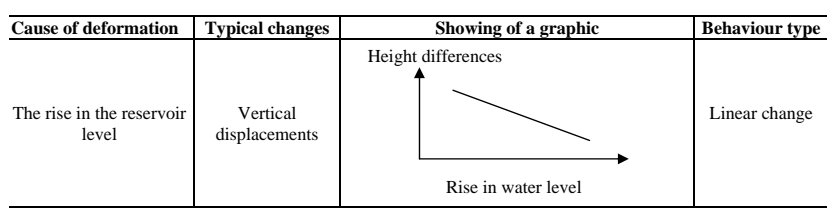

In Eq. (22), the unknown movement parameters consist of position, velocity (first derivative of position according to time), acceleration (second derivative of position according to time), and water level (first derivative of position according to water level changes). The four unknown parameters can be calculated using the Kalman-Filter technique with four measurement periods. To compute the movement parameters of the points with the Kalman-Filter technique, equations of position (Eq. 22), velocity, acceleration, and water level can be written as below.

$v_{x j}^{(i)}=v_{x j}+\left(t_{i}-t_{i-1}\right) a_{x j}$

$a_{x j}^{(i)}=a_{x j}$

$b_{x j}^{(i)}=b_{x j}$

Equatiopns (22), (23), (24), and (25) can be represented in matrix form, as given in

$\overline{Y_{i}}=\left[\begin{array}{c}x \\ v_{x} \\ a_{x} \\ b_{x}\end{array}\right]_{i}=\left[\begin{array}{cccc}I & I\left(t_{i}-t_{i-1}\right) & I \frac{1}{2}\left(t_{i}-t_{i-1}\right)^{2} & I\left(W L_{i}-W L_{i-1}\right) \\ 0 & I & I\left(t_{i}-t_{i-1}\right) & 0 \\ 0 & 0 & I & 0 \\ 0 & 0 & 0 & I\end{array}\right]\left[\begin{array}{c}x \\ v_{x} \\ a_{x} \\ b_{x}\end{array}\right]_{i-1}$

Equation (26) is the functional model of the dynamic model. The stochastic models of the dynamic model are formed with Eq. (19), which is the cofactor matrix of the movement parameters in the Kalman-filter process. The functional and stochastic models are solved by a least-square adjustment. The parameters of position (height changes), velocity, acceleration, and water level were included in this process. The dynamic model was calculated step-by-step as the kinematic case. Results are shown in Table 9. where a priori variance $\left(m_{L}\right)$ was taken from the ${ }^{a}$ Linear Model. A posteriori variance $\left(m_{S 5}\right)$ was computed from ${ }^{d}$ Square Model. $T=m_{S 5}^{2} / m_{L}^{2} . q$ is the $F$-distribution value. According to Koch (1999), if $T<q$, the global test is valid. As can be seen from Table 9, global test value $\left(T_{S 5}\right)$ are little than the $\alpha$-percentage point of the $F$-distribution value $\left(q_{S 5}\right)$ for a confidence level of $\alpha=0.05$. Thus, the square model can be viewed as accurate enough for this confidence level. That is, the global test of the dynamic model is valid.

To decide about an expansion of the kinematic model with the water level parameter, statistical tests were performed. To perform expanded model test, a priori variance $\left(m_{S 5}\right)$ was taken from the ${ }^{d}$ Square Model. A posteriori variance of expanded model $\left(m_{S 6}\right)$ was computed from parameters of the
Table 9. Statistical tests of the dynamic model.

\begin{tabular}{ll}
\hline${ }^{\mathrm{d}}$ Square Model (Postion + Velocitiy + Acceleration + Water Level) \\
\hline Global Test & Expanded Model Test \\
$\mathrm{m}_{L}$ & $\mathrm{~m}_{S 5}$ \\
$\mathrm{~m}_{S 5}$ & $\mathrm{~m}_{S 6}$ \\
$\mathrm{~T}_{S 5}$ & $\mathrm{~T}_{S 6}$ \\
$\mathrm{q}_{S 5}$ & $\mathrm{q}_{S 6}$ \\
0.695 & 0.843 \\
0.843 & 3.121 \\
1.472 & 13.707 \\
1.825 & 2.061 \\
$\mathrm{~T}<\mathrm{q}$ & $\mathrm{T}>\mathrm{q}$ \\
Model is VALID & Model can be EXPANDED \\
\hline
\end{tabular}

Note:Decision = position + velocity + acceleration + water level ${ }^{\mathrm{d}}$ December 2003-March 2004-November 2004-April 2005.

expanded model. The test value $\left(T_{S 5}\right)$ were computed with the $m_{S 6}$ and $m_{S 5}$ values and compared with the F-distribution value $\left(q_{S 6}\right)$ to evaluate whether the expansion of the model was significant or not. According to Koch (1999), if $T_{S 5}>$ $q_{S 6}$, the expanded model test is valid. As can be seen from Table 9 , the expanded model test value $\left(T_{S 5}\right)$ is larger than the $\alpha$-percentage point of the $F$-distribution value $\left(q_{S 6}\right)$ for a confidence level of $\alpha=0.05$. That is, the expanded model test of the dynamic model is valid. Thus, the expansion of the dynamic model with other causative force can be carry out.

The most appropriate functional model for the dynamic model is stated in the "decision" note at the bottom of Table 9. The movement parameters (vertical displacement, velocity, acceleration, Water Level) were computed and the results of the object points for the December 2003-March 2004-November 2004-April 2005 are given in Table 10. Here, every parameter was divided by its standard deviation, and test values $\left(T_{d h}, T v_{h}, T a_{h}, T b_{h}\right)$ were computed. These values were compared with the t-distribution value $\left(q_{t}\right)$ to evaluate whether they were significant or not. Where parameters have significantly effect, a (+) sign is shown; otherwise, a (-) sign is shown in decision column.

\section{Discussion}

Three methods were applied to the total station height data of the control network of the Yamula Dam. The starting point of this evaluation was a free-network adjustment for each measuring epoch resulting in adjusted heights, the estimated variances of unit weight, and the estimated variancecovariance matrices. Results of three deformation models for object points located on the dam are shown in Tables 1, 2, 4, 5 and 10. These tables indicate that all object points except for 19 and 20 on the dam had significant movements. When 
Table 10. Movement parameters for December 2003-March 2004-November 2004-April 2005.

\begin{tabular}{|c|c|c|c|c|c|c|c|c|c|c|c|c|}
\hline${ }^{a}$ P.N. & \multicolumn{3}{|c|}{ Height Difference $(\mathrm{cm})$} & \multicolumn{3}{|c|}{ Velocity unknowns $\mathrm{cm} / \mathrm{month}$} & \multicolumn{3}{|c|}{ Acceleration unknowns $\mathrm{cm} / \mathrm{month}^{2}$} & \multicolumn{3}{|c|}{ Water level $\mathrm{cm} / \mathrm{m}$} \\
\hline 19 & -0.12 & 0.52 & - & 0.00 & 1.24 & - & 0.00 & 1.33 & - & 0.00 & 0.23 & - \\
\hline 21 & -5.40 & 16.15 & + & -0.99 & 10.35 & + & -0.05 & 8.78 & + & -0.25 & 9.49 & + \\
\hline 22 & -7.42 & 20.90 & + & -1.08 & 13.24 & + & -0.06 & 10.69 & + & -0.33 & 12.44 & + \\
\hline 23 & -11.95 & 31.42 & + & -1.83 & 21.69 & + & -0.10 & 18.11 & + & -0.54 & 20.36 & + \\
\hline 24 & -5.82 & 16.32 & + & -0.89 & 11.36 & + & -0.05 & 9.19 & + & -0.28 & 10.47 & + \\
\hline 27 & -2.90 & 9.81 & + & -0.56 & 7.77 & + & -0.04 & 6.84 & + & -0.17 & 6.75 & + \\
\hline
\end{tabular}

${ }^{\mathrm{a}}$ Point number, ${ }^{\mathrm{b}}$ Vertical displacement, ${ }^{\mathrm{c}}$ Velocity, ${ }^{\mathrm{d}}$ Acceleration, ${ }^{\mathrm{d}}$ Water level parameter

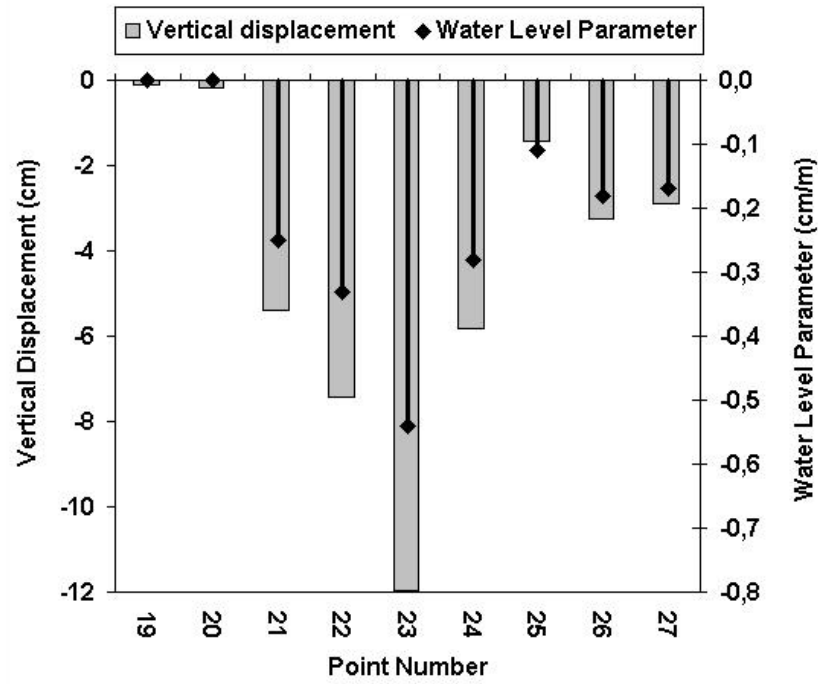

Fig. 4. Relationship between vertical displacements and water level parameters.

results of the static (Tables 1 and 2), the kinematic (Tables 4 and 5), and the dynamic (Table 10) models are compared, it is noticed that the directions of the movement parameters computed with each model are the same. That is, results of the models are agree with each other. Results can be noted that height change, velocity, acceleration, and water level effect are maximum at the middle of the dam.

It can be seen from Table 1 and 2, that the static model determines only position parameters. The kinematic model can determine position, velocity and acceleration parameters. The static and kinematic models do not include the effect of the water level in the reservoir. The dynamic model also contains a water level parameter, which shows physical effect of the reservoir water level on the height of object points.

The acceleration and water level parameters have physical meanings. The sign of the acceleration parameter in de- cision column is very significant to be able to interpret the vertical displacements. If "the sign of the acceleration in decision column is positive", the velocity of the vertical displacements increases. That is, there is a significant velocity on the points. If "the sign of the acceleration in decision column is negative", the velocity of the vertical displacements decreases. That is, there is not a significant velocity on the points. When examining the acceleration parameters, it can be seen from Tables 5 and 10 that the signs of the accelerations in decision column except for 19 and 20 are positive. This means that all object points (except for 19 and 20) show an increase of velocity with time.

The sign of the water level parameter is also significant to be able to interpret the effect of the reservoir water level on the settlements. When analyzing the sign and the magnitude of this parameter, the effect of water level on point settlements can be determined. If "the sign of the water level parameter in decision column is positive", a rise in the reservoir level causes settlements. If "the sign of the water level parameter in decision column is negative", there is not any settlements. When examining the water level parameters, it can be seen from Table 10 that the signs of the water level parameter in decision column except for 19 and 20 are positive. This means that all object points (except for 19 and 20) show significant settlements with a rise in the reservoir level.

The dynamic model shows the relationship between the rise in reservoir water level and the observed structural vertical deformation of the dam. This situation can be seen in Fig. 4. When examining the water level parameters, it can be seen (Fig. 4) that the rising water level increases the subsidence velocity of all object points (except for 19 and 20). That is, all object points (except for 19 and 20) were affected by the rise in water level during to first filling period. A more realistic deformation analysis as compared with the other geodetic models can be done with the developed dynamic model which determines the causes of the deformation. 


\section{Conclusions}

This article deals with the modeling of the relationships between the vertical displacements and the reservoir water level based on a new dynamic analysis method developed for the Yamula Dam. This analysis studies and identifies how the rising reservoir level affects the vertical deformations during the first filling period. The available 1.5-year four epochs records of the Yamula Dam indicated that all object points (except for 19 and 20) were unstable. The analysis of the reservoir water level changes by the dynamic model clearly indicates that the reservoir water level changes are an important triggering factor for the Yamula Dam deformations. The developed dynamic analysis method mentioned above is capable of determining the relationships between the vertical displacements and the rise in reservoir water in addition to velocities and accelerations of displacements. With the identified model, the simulation of the dynamic behaviour of the dam is possible considering the rise in the reservoir water. As expected, the vertical displacements were affected by the reservoir water level changes. The presented examples of modeling the dam deformation due to pressure of water shows that the predicted displacements are of the magnitude that can easily be detected by geodetic measurements.

Acknowledgements. The Ayen Energy Joint-Stock Company provided the four data sets used in this paper. The writer thanks M. Sari for his help in the construction of the mathematical model of the dynamic model.

Edited by: M.-C. Llasat

Reviewed by: two referees

\section{References}

Bayrak, T. and Yalçınkaya, M.: A kinematic analysis program for deformation monitoring, Proc. 11th Int. Symp. on Deformation Measurements, Greece (Santorini), 437-445, 2003.

Caspary, W. F.: Concepts of network analyses, edited by: Rüger, J. M., School of Surveying, University of New South Wales, New South Wales, Australia, 1987.

Chrzanowski, A. S., Chrzanowski, A., and Massiera, M.: Use of deformation monitoring results in solving geomechanical problems-case studies, Eng. Geol., 79, 3-12, 2005.
Denli, H. H. and Deniz, R.: Global congruency test methods for GPS networks, J. Surveying Eng., 129(3), 95-98, 2003.

Grewal, M. S. and Andrews, A. P.: Kalman Filtering Theory and Practise, Printice Hall, Englewood Cliffs, New Jersey, 1993.

Heunecke, O.: Zur identification und verifikation von deformationsprozessen mittels adaptiver KALMAN-Filterung, Wissen. Arbet. Der Fahricht. Vermess, Der Universitat Hannover, Nr. 208, 1995.

Koch, K. R.: Parameter Estimation and Hypothesis Testing in Linear Models, Springer-Verlag, Berlin, 1999.

Kuhlman, H.: Kalman-filtering withcoloured measurement noise for deformation analysis, Proc. 11th Int. Symp. on Deformation Measurements, Greece (Santorini), 455-462, 2003.

Kulkarni, M. N., Radhakrishnan, N., and Rai, D.: Global Positioning System In Disaster Monitoring Of Koyna Dam, Western Maharastra, Survey Review, 38(299), 629-636, 2006.

Niemeier, W.: Statistical tests for detecting movements in repeatedly measured geodetic networks, Proc. 6th Int. Symp. On Recent Crustal Movements, California, 335-351, 1977.

Pelzer, H.: Statische, kinematische und dynamische punktfelder, Vortrage des Kontaktstudiums, Geodatische Netze in Landesund Ingenieuvermessung II, Hannover, 225-262, 1985.

Pelzer, H.: Application of kalman- and wiener-filtering on the determination of vertical movements, Symp. Height Determination on Recent Vertical Crustal Movements Western Europe, Determination of Height Changes, Dümmler, Hannover, Germany, 539$555,1986$.

Pytharouli, S. I. and Stathis, C. S.: Ladon dam (Greece) deformation and reservoir level fluctuations: evidence for a causative relationship from the spectral analysis of a geodetic record, Engineering Structures, 27, p. 361-370, 2005.

Ren, D. and Ding, X.: Dynamic deformation analysis of open pit slopes. Proceedings of Fig 8th International Symposium on Deformation Measurements, Hong Kong, 1996.

Welsh, W.: Geodesy-The Challenge of The Third Millennium, ISBN 3-540-43160-8, Springer Verlag, Berlin Heidelberg, New York, 393-399, 2003.

Yalçınkaya, M.: Monitoring crustal movements in west Anatolia by precision leveling, Journal of Surveying Engineering, 129(1), 44-49, 2003.

Yalçınkaya, M. and Bayrak, T.: Comparison of static, kinematic and dynamic geodetic deformation models for Kutlugün landslide in northeastern Turkey, Natural Hazards, 34, 91-110, 2005.

Yalçınkaya, M. and Bayrak, T.: Dynamic model for monitoring landslides with emphasis on underground water in Trabzon province, J. Surveying Eng., 129(3), 115-124, 2003. 